\title{
EREBEA
}

Revista de Humanidades

y Ciencias Sociales

NúM. 4 (2014), pp. 353-368

ISSN: 0214-0691

\section{¿ARTE O FALACIA? EL PINTOR Y FALSIFICADOR HÚNGARO ELMYR DE HORY}

Clara Zamora Meca

Universidad de Sevilla

RESUMEN

Durante la segunda mitad del siglo XX tuvo lugar un sonoro y mediático caso de falsificaciones de obras de arte. Un pintor húngaro, afincado en Ibiza, era acusado de haber realizado un sinnúmero de dibujos y pinturas de varios maestros postimpresionistas haciéndolos pasar por obras auténticas. El caso conmocionó los cimientos del mercado del arte vigente. Hizo que se replanteasen cuestiones básicas relativas a la autoría de las obras y a los valores en torno a los que giraban la venta y adquisición de piezas artísticas, así como los derechos e intereses culturales de los artistas, coleccionistas, museos e, incluso, naciones enteras deseosas de velar por su patrimonio cultural. Las necesidades provocadas por la sociedad del bienestar supusieron el contexto idóneo para que este fraude tomara las dimensiones de un fenómeno social, cultural y económico sin precedentes conocidos.

Palabras Clave

Elmyr de Hory, arte contemporáneo, falsificación, mercado del arte, autentificación de obras de arte.

Fecha de recepción: 22 de abril de 2014 Fecha de aceptación: 23 de octubre de 2014
ABSTRACT

During the second half of the twentieth century a sound and newsworthy case of art falsification took place. A Hungarian painter who used to live in Ibiza, was accused of having made a number of drawings and paintings and making them seem like authentic artworks. The case shocked the foundations of the art market force at the time. It questioned works authorship and the values around which the sale and acquisition of art works were founded, but also concerned the cultural rights and artists, collectors, museums interests, and even entire nations to eagerly re-think about their cultural heritage. The needs created by the welfare state became the ideal context for this fraud to take social, cultural and economic unprecedented known dimensions.

KEYWORDS

Elmyr de Hory, contemporary art, falsification, art market, art authentication. 

"Pues si el alma, al imaginar presentes las cosas que no existen, supiera al mismo tiempo que no existen, atribuiría sin duda esa potencia imaginativa a una virtud y no a un vicio de la naturaleza; sobre todo, si esa facultad de imaginar que el alma posee dependiese de una sola naturaleza, esto es, si esa facultad de imaginar fuese libre".

Baruch de Spinoza, Ética (escolio)

En pintura, el estímulo sensual derivado de la contemplación de una obra debe prevalecer sobre el corolario intelectual que la propia obra encierre o el mensaje implícito que trate de transmitir. La sensación interior que resulta de la percepción a través de la vista entronca directamente con el hedonismo. Cabe aquí cuestionarnos si es preciso creer que los objetos han de ser considerados artísticos en virtud de sus propiedades intrínsecas y, si la respuesta es afirmativa, plantearse cuáles son dichas propiedades. La obra de arte nace de la mano del creador o artista. Para Fernando Savater "el creador es quien fabrica algo que sin él nunca hubiera llegado a ser, el que trae algo al mundo -grande o pequeño- que sin él nunca podría haber existido precisamente de ese modo y no de otro más o menos parecido" ${ }^{1}$. Especial relevancia toma en esta reflexión que planteo la alusión a la exclusividad en la ejecución de las obras del citado creador. En estos términos continúa Savater: "Las obras de arte no son posibilidades o cualidades realizadas de lo que previamente ya hay, sino que brotan de la personalidad misma de los artistas que las llevan a cabo. Se les parecen, reflejan tanto la forma de ser de quien las hace como la realidad del mundo de las que pasan a formar parte. El artista no es el primero en descubrir o lograr algo, sino el único que podía crearlo a su insustituible modo o manera...”. Tras esta contundente afirmación, ¿en qué lugar queda el falsificador de obras de arte?

En el extremo contrario, la audaz aseveración "todos los cuadros son falsos mientras no se demuestre lo contrario" articulada por Manuel Vicent ${ }^{2}$ es una provocación que nos hace pensar sobre la certeza con la que se nos muestran las pinturas en los museos sin que reparemos en reflexionar si algunas de éstas podrían ser falsas o estar mal atribuidas. Y, en el caso de que así fuera, si es lícito que se expongan como obras de arte porque cumplen los requisitos que éstas deben

1 Fernando Savater, Las preguntas de la vida. Barcelona: Editorial Ariel, S.A., 1999, p. 237.

2 Manuel Vicent, Mitologias. Madrid: Editorial Alfaguara, 2012. 
tener. El mismo Vicent se remonta al Renacimiento italiano para dejar constancia de que el propio papa Julio II fue víctima del engaño. Y afirma que Miguel Ángel Buonarroti le vendió como esculturas griegas algunas que él mismo había esculpido. En cualquier caso, la relación entre Julio II y Miguel Ángel, salpicada de arrebatos de orgullo y de ira, propios de dos caracteres muy marcados ${ }^{3}$, legó a la humanidad obras artísticas de un interés ilimitado, que ilustran uno de los episodios más sugestivos de la historia del arte.

Es de nuevo el escritor Manuel Vicent quien afirma que "demostrar que un cuadro es falso es casi tan difícil como demostrar que es auténtico. Este detalle estuvo a punto de llevar a la horca al copista de Vermeer, autor de una versión perfecta de Los discípulos de Emaús, quien se llevó su secreto a la tumba" ${ }^{4}$. Han van Meegeren (1889-1947) fue un pintor y retratista holandés, que ha pasado a la historia como uno de los más ingeniosos falsificadores de arte del siglo $\mathrm{XX}^{5}$. Empleaba pigmentos naturales y pintaba sobre cuadros del siglo XVII, de los que previamente había rascado la pintura original, pero nunca desveló cómo conseguía el craquelado propio de la época, cómo disolvía las tintas viejas y, a fin de cuentas, cómo envejecía el lienzo. No fue descubierto porque se dudara de la autoría de sus falsificaciones, dado que muchos, por ejemplo, pasaron siempre por auténticos Vermeer. Fue el mariscal Hermann Goering (1893-1946) quien parece que compró uno de estos falsos Vermeer y fue su vendedor, para salvar su vida tras la Segunda Guerra Mundial, quien dio el nombre de van Meegeren como propietario inicial del cuadro. Sea como fuere, después de su muerte, seguía la controversia entre historiadores del arte y científicos sobre las técnicas por él empleadas. Es justo mencionar a este artista holandés como mediático precursor de nuestro objeto de estudio. En su caso existía la dificultad añadida de centrarse en un artista del S. XVII frente a los artistas del XX que falsificó de Hory; no obstante, hay que reconocer el valor ańadido de este último al ser un falsificador polifacético, ya que Meegeren, según queda constancia, se limitó a imitar a uno de los más famosos artistas holandeses. En cualquier caso, si la aportación de ambos a la historia del arte tiene algún valor es, sin duda, el de suscitar el debate y, por ende, el pensamiento sobre la autenticidad y el valor de una obra de arte.

Para el profesor de la Universidad de París Jacques Aumont, la autentificación aplicada al arte es una cuestión de origen, de firma, de asignación. Autentificar

3 La novela histórica de Irving Stone: La agonía y el éxtasis, editada por Salamandra, recoge las relaciones de Miguel Ángel con sus mecenas más importantes.

4 Manuel Vicent, "Van Meegeren, la vanidad del falsificador". Diario El País, 22 de mayo 2010.

5 En la primavera de 2010, el Museo Boymans Van Beuningen de Rotterdam le dedicó una exposición a Han van Meegeren, poniendo así de manifiesto su reconocimiento a este artista como ejecutor de unos falsos Veermer de una excelencia tal que los hacían dignos de ser expuestas en este museo, uno de los principales de los Países Bajos. 
una obra es asegurar que ha sido creada por una personalidad dada y conocida ${ }^{6}$. La pintura es el arte en que con más evidencia ha sido necesario esta determinación de la autoría. No por una cuestión de índole ontológica, pues no es la naturaleza propia de las artes plásticas diferente a la música o la literatura ${ }^{7}$ (artes en las que también hay constancia de obras falsas o mal atribuidas), sino por cuestiones meramente económicas: son elevadísimas las cifras que se ponen en juego con la atribución o no de "Los jugadores de cartas" a Paul Cézanne, a Edvard Munch "El grito" o los Vermeer a Van Meegeren.

Dentro de la noción de autenticidad habría que especificar lo auténtico distinguiéndolo de lo original. Esta matización es especialmente necesaria en las artes de lo reproducible y de lo múltiple, como es el grabado. Un grabado de Goya puede ser auténtico (hecho a partir de las planchas grabadas por el artista), pero puede no ser una tirada original. Esto es lo que se encuentra frecuentemente en el mercado: tiradas realizadas con posterioridad a la muerte del artista, pero que pasan por auténticas, aunque no son originales. Así son muchos de los grabados de Durero o Rembrandt que circulan en el mercado del arte actual. También sería necesario aclarar el fenómeno de la copia y la reproducción de las obras. Si lo hace el propio autor es una copia; si lo hace otro, con intención de que parezca hecho por el autor, se convierte en falsificación. La noción de autenticidad está llena, pues, de matices que marcan su carácter ontológico y le imbrican de cierto matiz policíaco.

La falsificación atenta directamente contra el valor de la autenticidad, valor intrínseco a unos objetos-testimonios del pasado únicos. La realización de piezas de arte falsas enlaza directamente con la pasión por el arte. El coleccionismo y la necesidad de arte que caracteriza nuestra era es una típica expresión del capitalismo avanzado y de una sociedad postindustrial, como claro exponente del paso de una economía de subsistencia a la reciente de opulencia. Una obra de arte se adquiere para satisfacer deseos y necesidades personales que pueden entrar en la dialéctica del propio valor de uso (decorar un hogar, satisfacer el placer estético, etc.). Dichas complacencias son las que declaran los coleccionistas en primer término, pero en realidad son también las menos importantes ${ }^{9}$. Esta demanda es la que directamente suscita el mercado ilícito de obras de arte. El mal juicio y la ambición abocan a muchos coleccionistas a caer en sus redes. Incluso

6 Jacques Aumont, La estética hoy, Madrid: Editorial Cátedra, 2001, p. 139.

7 Valga como ejemplo la atribución durante años de la cantata "Schlage doch, gewünschte Stunde", atribuída durante mucho tiempo a Johann Sebastian Bach (BWV53) y compuesta parece ser por Georg Melchior Hoffman hacia 1705. Una cantata especialmente bella, que trata el tema de la liberación del hombre por la muerte.

8 Este cuadro, uno de los más caros jamás vendidos, lo adquirió la casa real de Catar por 191,6 millones de euros en 2012.

9 Angela Vettese, Invertir en arte. Madrid: Ediciones Pirámide, 2002, p.24. 
en casos en que se descubre el engaño o fraude es común no denunciarlo, ya que hacerlo supondría reconocer un insulto a su inteligencia así como la pérdida del valor material de la pieza. En ocasiones, se llega a un acuerdo con el vendedor, que suele pertenecer al círculo legal del arte y evitar así el escándalo que dañaría su reputación profesional.

Las falsificaciones se dan en la actualidad, sobre todo, en pintura y obra gráfica contemporánea. No obstante, las falsificaciones se llevan a cabo con piezas de todas las épocas. No es nueva la intención fraudulenta de sumergir debajo del mar ánforas y otras piezas de barro durante tiempo prolongado para conseguir la pátina adecuada y lograr así pasarlas por piezas fenicias, griegas o romanas. Lo que más se falsifica es la pintura, por ser el arte con mayor demanda, y el período oscila entre el siglo XIX y nuestros días. El falsificador tiende a imitar obras de artistas muy prolíficos, con una extensa obra, poco controlada por sus herederos. Las complejas técnicas que se utilizan para comprobar la autenticidad de la pintura antigua -los exámenes químicos y radiológicos que delatan la fecha de los materiales utilizados- no son válidas para la obra contemporánea. No esclarecen nada, pues todos son materiales del siglo XX. Como ejemplo singular, cabe destacar el de Salvador Dalí, que desarrolló un complicado montaje comercial con métodos poco ortodoxos: firmó en vida una cantidad ingente de papeles en blanco que han permitido la reproducción sin control de su obra ${ }^{10}$. Fue el propio Dalí quien incitó la práctica de firmar hojas de papel litográfico en blanco a millares a partir de 1970, hasta el punto de que en 1991 se encontraron 50.000 litografías falsas ${ }^{11}$. Lo que hace extraordinario este caso concreto es el hecho de que son falsificaciones con firma auténtica.

Fuera de España son frecuentes las imitaciones de Bacon, Lichtenstein y Warhol. Suelen ser obra gráfica y, en muchos casos, lo que se realizan son tiradas superiores a las definidas por el autor, aunque salen de las planchas originales. Estos serían ejemplos de obras igual de auténticas que las de la edición venal, pero no son originales y además rompen las pautas de mercado. Los galeristas se defienden de este mal que les acecha afirmando que es muy difícil que las falsificaciones entren en el circuito de las galerías prestigiosas, ya que ellos saben las múltiples maneras que existen para comprobar la autenticidad. En algunos museos norteamericanos se ha llegado, incluso, a poner un marcha un programa formativo en el que se utilizaban las obras falsas como instrumento para educar a los especialistas en el reconocimiento de las verdaderas ${ }^{12}$. Si se trata de artistas vivos, se consulta con ellos directamente la autoría; en otros muchos casos, hay

10 El reportaje del periodista catalán Alfons Quinta aporta datos concretos sobre este escandaloso fraude. Fue publicado por el diario El País el 13 de marzo de 1981, aún en vida del artista.

11 El País, 15 de abril de 1993.

12 Harvard Art Museums (Cambridge, Massachusetts), en concreto el Fogg Museum tiene una colección de falsos que cuenta con tres Matisses de Elmyr de Hory. 
herederos que pueden autentificar la obra; y, por último, están las fundaciones y los museos, que tienen documentada prácticamente toda la obra existente. La primera sospecha para ellos es la del bajo precio y luego la aparición súbita de mucha obra de un mismo autor. En España, el órgano encargado de evitar que se produzcan casos de estafa y sus perjuicios económicos y desprestigios de instituciones y/o personas es la Brigada de Patrimonio Histórico del Cuerpo Nacional de Policía. Su inspector jefe explica el procedimiento que realizan en la actualidad en estos términos: "ahora lo que hacemos cuando detectamos una obra falsa no es incautarla sino recabar la opinión técnica de un experto e iniciar una investigación sin alertar a nadie. Vigilamos la obra fraudulenta para que no se venda, rastreamos su origen haciendo seguimiento de los elementos sospechosos, hasta llegar a los almacenes y los locales donde se produce el trabajo de falsificación. Sólo en ese momento solicitamos una orden judicial para efectuar un registro y las posibles detenciones" ${ }^{13}$.

Tras este análisis de contexto y sin más preámbulos, vamos a pasar al análisis de la figura de Elmyr de Hory (Budapest 1906 - Ibiza 1976), cuya trayectoria vital y creativa continúa hoy seduciendo a todo el que se asoma a la historia de este personaje y a lo que supuso en la historia del mercado del arte contemporáneo. El carácter novelesco de su vida, confusa, llena de detalles no del todo confirmados, así como la forma en que desmontó muchas de las convicciones existentes sobre la figura del autor y la originalidad artística le otorgan un merecido puesto en la historia del arte del siglo XX. Era húngaro, hablaba cinco idiomas, era hedonista, refinado, con gracia natural, pero también ocioso y débil de carácter. Los datos biográficos nos vienen a través del libro que escribió en 1969 su amigo Clifford Irving ${ }^{14}$. Pero, dado que éste fue detenido unos años más tarde por escribir la biografía falsa del magnate Howard Hughes ${ }^{15}$, los datos no son del todo fiables. Junto al propio Elmyr, la historia de su picaresca cultural implica a tres personajes más: Fernand Legros y Real Lessard, pareja sentimental formada por dos astutos jóvenes que ejercieron de marchantes, y, en el papel de ingenua víctima, el millonario del petróleo texano Algur Hurtle Meadows. El coleccionista americano fue el que desenmascaró toda la trama dudando de algunas de las obras que había adquirido para su colección. ¿Eran estas piezas dudosas de la colección Meadows de Texas nada más que la punta de un iceberg?

13 A. Arnalte y P. Mateos, "El negocio de las falsificaciones", Revista Descubrir el arte, no 32, (Octubre 2001), pp.48-55.

14 Clifford Irving, ;Fraude!La historia de Elmyr de Hory. El pintor más discutido de nuestro tiempo. Barcelona: Editorial Norma, 2009.

15 Tras reconocer su delito, pasó diecisiete meses en prisión. El caso fue llevado al cine por el director sueco Lasse Hallström en "La gran estafa" (The Hoax, 2006), con Richard Gere en el papel de Irving. 
Según nos cuenta Clifford, la familia de Elmyr era de grandes terratenientes: "su madre procedía de una familia de banqueros judíos, que siempre había servido a los reyes del Imperio Austrohúngaro; su padre, en el período de entreguerras, fue nombrado embajador de Hungría ante el gobierno turco, y luego, en dos repúblicas sudamericanas" ${ }^{16}$. Estos datos no son nada fidedignos y menos cuando se constata que lo cita como único hijo de padre ricos y sabemos de la existencia de un cuadro del reconocido retratista húngaro Philip de László (Budapest 1869Londres 1937) fechado hacia 1912 y titulado "Elmyr y su hermano Stephen"17. Este dato nos hace poner en entredicho cualquier información procedente de la biografía novelada de Irving; no obstante, es una fuente obligada para cualquiera que desee acercarse a Elmyr de Hory ${ }^{18}$. De lo que no cabe duda es de que debió de ser un joven bien parecido, de finos modales y con sensibilidad, y cuya homosexualidad marcó gran parte de su vida.

Con dotes artísticas destacadas desde muy joven, Elmyr pasó por la Escuela de Budapest y, en su búsqueda de libertad, consiguió que su madre le mandara a estudiar primero a Munich y luego a París. Fue un alumno aplicado en la academia dirigida por Fernand Léger. Vivió en Montparnasse en el cénit de su época de oro, los años veinte, y, como bon vivant nocturno, coincidió en los ambientes intelectuales con Hemingway, Picasso, Man Ray, Duchamp, Peggy Guggenheim, André Breton, James Joyce,... Recibía de su familia cuanto dinero necesitaba. Su vida oscilaba entre la bohemia del mundo parisino de los artistas y la veleidosa sociedad adinerada internacional. Irving señala en su novela que en 1926 expuso en el Salón de Otoño ${ }^{19} \mathrm{y}$, en paralelo, fue pintando retratos de amigos ricos como el príncipe Yussoupov o el duque de Kent.

La Segunda Guerra Mundial cambió por completo el destino de Elmyr de Hory. Según cuenta su amigo y biógrafo, sus padres habían muerto y la fortuna familiar había sido confiscada por los alemanes. En la Europa de la posguerra era un pintor con habilidades, pero sin reconocimiento, que no era ya tan joven y cuyos caros gustos eran un difícil e inevitable compañero de viaje. Las galerías de París no apostaban por los paisajes y desnudos que él les ofrecía. En este punto de la historia tiene comienzo su carrera como falsificador de obras de arte, carrera

16 Irving, ;Fraude!La historia de..., p. 25.

17 Este cuadro se encuentra en la colección Mark Forgy, que fue la última pareja sentimental de De Hory y su heredero universal.

18 Otra fuente de consulta es Mark Forgy: The Forger's Apprentice: Life with the World's Most Notorious Artist. Amazon, 2012. En ella, Forgy relata sus siete años de vida junto al húngaro e intenta esclarecer su verdadera historia revisando cartas y documentación en diversos archivos.

19 Las exposiciones realizadas en el Salón de Otońo en París fueron de una relevancia extraordinaria. En ellas, que se fueron celebrando anualmente desde el año 1903, se dio a conocer al público el movimiento impresionista y surgió el nacimiento oficial del Fauvismo con la exposición de 1905. 
que duró más de veinte años, tuvo en tensión a cinco continentes y le concedió su deseado lugar en la historia del arte. A pesar del tono novelado de esta anécdota que describe Irving, creo que es interesante su transcripción, porque transmite lo fortuito que debió ser el desencadenante de su singular destino:

"Elmyr era un hombre arruinado aquella tarde de abril de 1946, en que lady Malcolm Campbell, una amiga que vivía en el suntuoso hotel Jorge V, visitó su estudio de la calle Jacob y por casualidad se fijó en uno de los dibujos que colgaban en la pared diciendo: "Elmyr... eso es un Picasso, ¿no?”

No era un Picasso. Era un De Hory, una línea de cabeza de muchacha sin firma y sin marco. Elmyr sonrió a su buena amiga lady Campbell.

- ¿Cómo sabe que es un Picasso?- preguntó.

- Entiendo algo de Picasso -dijo con un cierto aire de autoridad, en tono indiferente-, y recuerdo que usted me dijo que le conocía bastante bien antes de la guerra. Hay un montón de esos dibujos de su período griego que no firmó. Es muy bueno. Dígame, ¿le gustaría venderlo?

- Bueno, ¿por qué no? -dijo Elmyr, suspirando levemente después de un rato-. ¿¿Cuánto me da por él?

El precio acordado fueron 40 libras esterlinas, con ese dinero podría vivir durante dos meses. El dibujo lo había hecho en diez minutos en una lluviosa tarde de marzo. Elmyr olvidó el incidente lo más pronto posible. Necesitaba imperiosamente el dinero, pero aun así, se sentía un poco culpable de haber engañado a una amiga (aun tratándose de una amiga rica). Tres meses más tarde, la elegante dama en cuestión volvió a Inglaterra. En una fiesta se llevó a una esquina al nervioso Elmyr:

-Querido, tengo que confesarle que me encuentro un poco incómoda con aquel dibujo de Picasso que me vendió. Tenía poco dinero en efectivo cuando estaba en Londres, y lo llevé a un tratante de obras de arte que conozco. Me dio 150 libras por él. Querido Elmyr, no se emocione así, ¿quiere comer conmigo en el Ritz mañana?

Rechazó la invitación para cenar en el Ritz, se dirigió en cambio a su estudio, consultó algunos catálogos viejos y luego pasó una hora haciendo dibujos a pluma en el llamado estilo clásico, de alrededor de los ańos 25 , a lo Picasso, mientras pensaba: ¿qué otra alternativa me queda? $\mathrm{Al}$ menos en la cárcel no me moriré de hambre"20.

Decía que había conocido a Picasso en París y le había regalado esos dibujos que en realidad había pintado él mismo sobre un papel viejo de antes de la guerra, 
que ya incluso amarilleaba por los bordes. Los dibujos se vendían y el dinero le permitía respirar. Sea como fuera el origen de la historia, la lucha interna del artista húngaro por continuar pintando su propia obra siendo fiel a sí mismo o lucrarse de la facilidad que había descubierto que poseía para imitar los trazos de otros artistas consagrados le acompañó toda la vida. Cuando se veía con dinero en los bolsillos, volvía a pintar su obra, intentando hacerse un hueco en el panorama artístico del momento. Así fue, por ejemplo, cuando consiguió que la Lilienfeld Gallery de la calle 57 de Nueva York, según relata Irving, le propusiera hacer una exposición individual. La exposición fue un éxito, pero social, pues la inauguración fue el acto estrella de la temporada. En cambio, desde el punto de vista artístico la crítica lo descalificó por poco original y desde el punto de vista económico fue un fracaso absoluto.

Llegado este momento de su vida, puso todo su énfasis en su carrera como falsificador. Estudió bien los materiales, buscando en librerías de viejo papel de los años veinte. Vivía entonces en los Estados Unidos, donde aparecía como el barón de Hory, un respetado caballero europeo, heredero de una importante familia y con un patrimonio artístico del que quería desprenderse poco a poco. Sólo sería el primero de los muchos pseudónimos ${ }^{21}$ que fue adoptando a lo largo de su carrera como falsificador.

Era el final de la década de los cuarenta, los dibujos de Picasso ${ }^{22}$ comenzaron a cansarle y fue aumentando su elenco de autores. Probó con Matisse ${ }^{23}$ y Renoir. $\mathrm{Su}$ éxito era la feliz combinación entre un meticuloso análisis y una habilidad extraordinaria. Las obras que realizaba se vendían fácilmente. Muchas de las "víctimas" de su modo de ganarse la vida eran los nuevos millonarios del petróleo y su urgente necesidad de poseer cultura instantánea. El deseo de felicidad originado por la cultura de la imagen y por el universo prodigioso del presente (aquí y ahora) que estaba entonces tomando cuerpo gracias a la publicidad y a la cultura de masas en auge era el contexto idóneo para que el requisito de poseer arte se convirtiera

21 Dory Boutin, Herzog, Louis Nassau, E. Raynal fueron algunos de los pseudónimos utilizados por Elmyr de Hory.

22 La obra de Picasso que imitaba tenía que ser anterior a los años treinta. El Catálogo Zervos, -una obra de 33 volúmenes que recopila la catalogación de la obra de Picasso entre 1932 y 1978, que fue dirigida por Christian Zervos y publicada en París por Cahierrs d'Art-, le limitaba la posibilidad de acercarse a la obra posterior a esa fecha, ya que debía quedar recogida en este catálogo para quedar autentificada.

23 Se centró especialmente en Matisse a partir de su muerte, el año 1954, con la idea de que el valor de sus obras aumentaría tras su desaparición. Pero debía tener prudencia, pues Marguerite Duthuit, hija del pintor francés, comenzó a confeccionar un catálogo con las pinturas de su padre y la reclamaban para que las autentificara. Marguerite murió en 1982 en París. Irving, en su novela, alude a ella poniendo en boca de Fernand Legros las siguientes palabras: "Si pudiera encontrar a alguien capaz de llevarle a esa mujer una caja de bombones rellenos de veneno, ese día me hubiera hecho millonario". 
en una imperiosa necesidad para una determinada clase social. En América, siendo quizás Dallas la capital de este fenómeno, Elmyr de Hory tuvo un éxito inmediato. Sus obras de artistas de la vanguardia europea eran exactamente lo que allí se demandaba. Vendió a museos de arte moderno y galerías de Nueva York, Chicago, Washington, San Francisco, Dallas, etc. Eran los ańos cincuenta.

Los marchantes de arte comenzaron a enriquecerse con lo que le habían comprado, mientras él seguía siendo un pintor desconocido. El tiempo pasaba y de Hory sentía que su talento no estaba del todo aprovechado. Era para él difícil, pero debía asumir que era un profesional consumado de la falsificación de obras de arte. Aceptada su verdadera profesión, fue comprometiéndose cada vez más con ella. De este modo, pasó del papel al lienzo con las complicaciones que eso suponía. Asimismo fue ampliando el número de artistas sobre los que trabajaba. El reconocimiento que fue adquiriendo la pintura impresionista a partir de los años cincuenta favoreció su labor. Con el auge de los maestros impresionistas y postimpresionistas, el precio de la obra de Elmyr iba alcanzando cifras elevadísimas. Conforme las pinturas pasaban de su estudio a una galería, y de ésta a un propietario particular y de éste a un museo, se hacía cada vez más incuestionable su autenticidad y su precio iba en aumento, aunque de las plusvalías de este proceso el pintor húngaro sólo recibía una mínima parte.

La vida nómada a la que estaba sometido, el cambio continuo de nombre y algún que otro incidente con marchantes y directores de museos ${ }^{24}$ comenzaron a hacerle sentir cierto recelo. En este preciso momento es cuando apareció en su vida Fernand Legros (1931-1983). De él decía Elmyr: "cuando yo lo conocí no distinguía una acuarela de un gouache, no podía distinguir un Cézanne de un Matisse, ni un Rafael de un Tiziano. Y continuó en su ignorancia abismal hasta el último día de nuestras relaciones. No tenía capacidad de observación: podía ver la misma pintura a diario durante seis meses y si se le enseńaba un mes después, ya no la reconocía. Era un hombre totalmente carente de gusto, pero explotó una veta increíble que estaba oculta totalmente por su rudeza: tenía el ingenio de los orientales, esa habilidad para embaucar. Era capaz de ejercer poder sobre uno, tenía una personalidad astuta y poderosa" ${ }^{25}$. El tercer miembro del trío era Réal Lessard, pareja sentimental de Legros.

Si Elmyr de Hory hubiera dejado esta labor en este momento previo a negociar con Legros, quizás nunca se hubiera dado a conocer y hubiera sido el falsificador más prolífico de la historia, honor que hubiera disfrutado furtivamente. Ya tenía para entonces una sorprendente cantidad de obras colgadas en museos, galerías

24 Irving relata un primer incidente con el marchante Frank Perls, que fue el primero en ver el infundio de algunos de sus dibujos. También menciona a la subdirectora del Museo Fogg de Arte de la Universidad de Harvard, Agnes Mongan, quien sospechó de unos dibujos de Modigliani y Renoir.

25 Irving, iFraude!La historia de..., p. 130. 
de arte y colecciones privadas. Nadie hubiera podido creer que todas ellas habían salido de la misma mano. A pesar de que el mundo del arte contemporáneo era un mundo reducido a escala internacional y que todos los profesionales se conocían entre ellos, Elmyr había sido capaz de eludir toda sospecha y pasar desapercibido, gracias a los pseudónimos y a su gran astucia. Ya para entonces habría ostentado un lugar en los anales de la delincuencia.

No llevaba ningún registro de las obras que producía y vendía, ni tomaba fotografías de ellas. Su desprecio por el mundo oficial del arte y su declaración de que no estaba arrepentido, así como su ego triunfante, nunca le permitirían reconocer la perversión del arte en la que estaba sumergido. Era la vanidad del falsificador. Se veía a sí mismo como un artista que no había sido valorado, una víctima a la que el sistema establecido no le había permitido convertirse en un pintor conocido por derecho propio. Para él, falsificar un Matisse o un Modigliani no era un delito, pues no perjudicaba a nadie.

En la década de los sesenta, de vuelta a Europa, sintió la necesidad de atar amarras y asentarse definitivamente. Ahora que tenía a sus marchantes particulares no tenía la necesidad de estar de aquí para allá con las obras debajo del brazo. Volvió la vista al Mediterráneo, el perpetuo cobijo de artistas y escritores exiliados. Un amigo le habló de la isla de Ibiza, que por entonces empezaba a ser conocida a escala internacional sobre todo por el movimiento hippie, como una isla fascinante: Ibiza tenía todo lo que iba buscando. Elmyr llegó a Ibiza en 1961. Entonces fue cuando Fernand le dijo "vivirás como Robinson Crusoe en tu pequeño paraíso de la isla del Mediterráneo. Nosotros correremos con todos los riesgos" 26 .

La mayoría de los marchantes de arte de mayor reputación admiten haber sido asaltados por Legros. También afirman haberlo erradicado inmediatamente. Según Irving, "hay un número tan asombroso de marchantes que pretenden haberle echado de su galería que uno se pregunta ¿a quién vendía?...”. La técnica empleada por Fernand se asentaba en el uso de un certificado de experto, que servía de prueba fidedigna sobre la autenticidad de la pieza que ofrecía. También se apoyaba en el historial del cuadro, es decir, certificados de anteriores propietarios. En ocasiones, ellos mismos pujaban por las obras en subastas con tal de que ésta se incluyera en el catálogo consiguiendo así un cierto seguro de autenticidad. En general, la polémica no giraba en torno a la real o falsa atribución de las obras, sino en torno a su precio. Con el boom económico que siguió a la posguerra, apareció mucha gente con dinero así como unos nuevos símbolos sociales, entre los que destacaba la posesión de importantes obras de arte. Ya no era suficiente con tener un buen coche; era necesario también tener un Picasso o un Matisse decorando el salón de la casa. Una nueva clientela, ambiciosa, boyante y distribuida por todos 
los continentes, era la receptora idónea para que el fraude pudiese llevarse a cabo y en las dimensiones en que tuvo lugar. Legros y Lessard no contaban mucho a de Hory ni tampoco eran honrados y ecuánimes con él. Ellos le manipulaban con una dosis perfecta y mínima de estímulo y dinero que asegurase que la gallina de los huevos de oro seguía produciendo. Como ejemplo de esta dosificada carga de estímulo y a modo de acicate le construyeron "La Falaise", en un terreno sobre un acantilado en Ibiza. La casa se convirtió en la residencia de lujo de la isla y allí el artista continuaba con su agitada y festiva vida social.

Fue en estos ańos, a mediados de los sesenta, cuando le presentaron a Legros en Dallas a un coleccionista y multimillonario del petróleo llamado Algur Hurtle Meadows $^{27}$. Irving, en la biografía de Elmyr, enumera incluso las obras que le vendió: "quince Dufys, siete Modiglianis, cinco Vlamincks, ocho Derains, tres Matisses, dos Bonnards, un Chagall, un Degas, un Laurencin, un Gauguin y un Picasso, todos pintados por Elmyr. Aproximadamente la mitad eran óleos. Así, Meadows se convirtió, según un periodista, en el hombre con la mayor colección de falsificaciones del mundo"28. Expertos en arte examinaron cuidadosamente la colección de maestros postimpresionistas y sus juicios fueron contundentes. Según relata Irving, contaron hasta cuarenta y cuatro pinturas falsas. Pero nadie en ese momento determinó que todas ellas habían salido de la misma mano. Para algunos, en ese instante, Legros había arruinado el mercado del arte. Meadows se convirtió sin remedio en la imagen viva de la codicia, un ingenuo acumulador de riquezas que compraba para elevar su prestigio, pero carente de criterio y de gusto. No obstante, hay que reconocerle la valentía de admitir que fue víctima de semejante fraude. Muchos otros coleccionistas, dando un paso para atrás, trataron de solucionar el caso directamente con las galerías o casas de subastas, pero manteniendo, ante todo, el anonimato. Una vez levantada la liebre, todo parecía muy evidente y lógico, pero no olvidemos que las obras de Elmyr habían engañado a los mayores expertos en arte, siendo colgadas en museos y colecciones privadas de todo el mundo.

Con los años, la difícil relación entre Legros y Lessard se fue deteriorando hasta un punto insostenible. Continuaron asociados en los negocios, conspiraban y vendían juntos, pero en el plano personal se convirtieron poco a poco en dos adversarios. El constante vaivén emocional de sus socios afectó también a Elmyr, que se sentía presionado por sus continuas y exigentes demandas. Una vez que estalló el escándalo, el húngaro mantenía la fantasía de que, como él no había vendido nada en España, las autoridades españolas no concederían la

27 Algur Hurtle Meadows (1899-1978) viajó a España hacia 1950 y quedó fascinado por la pintura del Siglo de Oro. Comenzó a formar la que quizás sea la colección de pintura española más importante de EE.UU. Su museo se inauguró en 1965 con obras de Velázquez, Ribera, El Greco, Murillo, Picasso, Miró, etc y, desde entonces, la colección continuó ampliándose sin parar.

28 Irving, ;Fraude!La historia de..., p. 205. 
extradición. Pero el tribunal madrileño demostró ser estricto. Según indica Irving, la acusación contenía una mezcla de cargos desde homosexualidad y convivencia con conocidos delincuentes hasta carecer de medios demostrables de subsistencia, pero no se le puso la pena de expulsión. En lugar de eso, se le sentenció a dos meses de prisión, y quizás más si aparecían otras pruebas. Era la tarde del 5 de diciembre del año 1976. "Querido -dijo a un amigo- voy a suicidarme". Una sobredosis de barbitúricos cumplió su deseo ${ }^{29}$.

¿Qué estaba pasando en aquellos años con el mercado del arte para que este hecho pudiera ocurrir y tuviera tanto éxito y repercusión?. El propio Elmyr reflexionó sobre ello:

"Es absolutamente desproporcionado el dinero que se paga en relación con el valor real de los cuadros. Si pensamos en artistas muertos hace tiempo, maravillosos, como Franz Hals o Rembrandt, y los otros grandes pintores del Prerrenacimiento, y nos damos cuenta de que algunos de sus cuadros se cotizan bastante menos que algunos de Miró, Renoir o Picasso, se le ponen a uno los pelos de punta. Realmente es increíble que alguien como Picasso, aún en vida, entre dos cigarrillos, hace un pequeño dibujo y eso se transforma inmediatamente en oro. He oído una historia de Fernand Legros, que había enviado uno de mis Picasso a Picasso para que certificara su autenticidad, y Picasso, que no estaba totalmente seguro, preguntó al que lo llevó: '¿Cuánto pagó el marchante por él?'. Le dieron una cifra fabulosa, unos 100.000 dólares, y Picasso dijo 'Bueno, si han pagado tanto, debe ser auténtico'. 'La situación de hoy fue creada artificialmente por un grupo de marchantes internacionales. Al público se le ha engañado’.

'Mi mejor obra nunca pudo ser vendida a las galerías a ningún precio, pero si les llevaba la misma con la firma de Picasso, estaban dispuestos a pagar lo que fuera. A mí me pareció todo esto tan increíble, ¿cómo diría?.. en una parte divertido, en parte triste, en parte repugnante'".

La posición de Elmyr de Hory como maestro de la falsificación de obras de arte es incuestionable, fuera como fuese realmente la dimensión del desastre que supuso en el mercado del arte internacional. Desde los comienzos de su carrera, en los años cuarenta, había producido una ingente cantidad de obras de artistas con estilos muy diferentes y todos ellos habían pasado por obras auténticas. De hecho, de no haber sido por los grandes problemas personales y las disputas de sus vendedores, Fernand Legros y Réal Lessard, puede que nunca se hubiera descubierto la verdad sobre Elmyr de Hory. Una vez descubierto el fraude, comenzó la paradoja y las obras atribuidas a los grandes maestros pero salidas

29 Irving, iFraude!La historia de..., p. 303. 
de los pinceles del sugestivo artista húngaro comenzaron a cotizarse a la alza. Tener un Modigliani por Elmyr de Hory era (y es) todo un privilegio. Con el paso del tiempo, de Hory se convirtió en el protagonista de sus obras y esto le condujo a lo que tanto había ansiado durante toda su vida: el doble honor de su reconocimiento como artista y el éxito comercial. Sólo así se explica la existencia de falsos Elmyr, que le convirtieron en el falsificador falsificado. A pesar de la fama mundial que consiguió este pintor húngaro, es obvio que el mejor falsificador de obras de arte de la historia es desconocido. Es o fue aquel que engañó o engaña y ha sido o es capaz de estar a la sombra.

En 1971, realizó una exposición en Madrid, en la sala Bruagut de calle Serrano no 27, con los cuadros que había firmado como Elmyr, obras realizadas "al estilo de", pero firmadas dignamente por su verdadero autor. Fue un éxito de crítica y económico. Éste fue quizás el reconocimiento como artista que tanto había anhelado en su juventud; el camino recorrido hasta conseguirlo había sido atípico, escandaloso y paradójico, pero certero. Orson Welles, cautivado por los encantos y la picaresca del húngaro, lo convirtió en 1973 en el protagonista del documental "Fraude" ( $F$ for Fake), junto a él su biógrafo y amigo Clifford Irving. En este largometraje con cierto aire delirante, el director de cine americano reflexiona y discurre sobre conceptos como la autenticidad y la ilegitimidad, la realidad y la apariencia: de nuevo, la figura y la producción de Elmyr de Hory como núcleo del debate en torno a qué es arte y cómo se articula su mercado. La última exposición que se ha llevado a cabo en España sobre este versátil personaje, demostrando así el interés que aún suscita, tuvo lugar en la Sala Goya del Círculo de Bellas Artes de Madrid entre los meses de febrero y mayo de 2013 y fue comisariada por Dolores Durán Úcar, quien planteó la muestra como "una invitación a debatir cuestiones fundamentales sobre la esencia de la obra de arte y el concepto de autoría. Pensamientos que han atormentado al hombre desde tiempos casi borrados. Fue Horacio quien dijo, allá por el siglo I a.C., que quien conoce mil obras de arte conoce mil fraudes. Y fue Rimbaud, muchos siglos después, quien resumió magistralmente ese laberinto: Yo es otro" ${ }^{30}$.

Todo lo expuesto pone de manifiesto cómo, en la medida en que el arte ha cobrado mayor importancia económica en nuestra sociedad, es más escandalosa la diatriba contra los derechos e intereses culturales de los artistas, coleccionistas o museos. Ya lo decía Walter Benjamin en 1936: "la obra de arte ha sido siempre fundamentalmente susceptible de reproducción. Lo que los hombres habían hecho, podía ser imitado por los hombres ${ }^{31}$ ".

30 Dolores Durán Úcar, "Yo es otro”, Proyecto Fake!. Madrid: Círculo de Bellas Artes, (2013), p. 9.

31 Benjamin Walter, La obra de arte en la era de su reproductibilidad técnica. Madrid: Editorial Taurus, 1973. 
Tradicionalmente, los historiadores del arte han contado con tres instrumentos para determinar la autenticidad de una obra de arte: los análisis científicos, la documentación histórica y la inspección visual por el ojo de un experto. El tercer mecanismo de apreciación va indisolublemente unido al concepto de factura. Según la RAE es la "manera de ejecutar algo", lo que podríamos especificar en pintura como la manera particular que tiene la mano de un artista de expresar su carácter y genio. Lo dijo Aristóteles: la forma es sustancia y el estilo es accidente ${ }^{32}$. Para el experto neoyorquino Eugene Thaw, los dos artistas más difíciles de imitar son Piet Mondrian y Pollock "porque su factura, muy compleja y personal, parece de entrada demasiado fácil de emular, especialmente si se observan las reproducciones -que aplanan la dimensionalidad de la superficie de su obra y eliminan la sensación de reflectancia a menudo cambiante de su factura-" 33 .

La International Foundation for Art Research (IFAR, www.ifar.org, Fundación Internacional de Investigadores sobre Arte) fue creada a finales de los ańos sesenta, tras descubrirse algunos importantes fraudes que, como éste de Elmyr de Hory, provocaron la desconfianza del público en el mercado del arte. Se estableció como marco legal y administrativo un ámbito por el que los expertos podían expresar opiniones sobre autenticidad con objeto de erradicar el fraude en el mundo del arte. Más tarde, el dominio de IFAR se amplió para incluir temas de propiedad, robos y legislación. Esta fundación creó, además, la primera base de datos sobre objetos de arte robados disponible para el público. Uno de los cambios que se ha detectado en las últimas décadas con objeto de sanear el mercado del arte es la aparición de numerosos catálogos razonados y de la aparición de comités de autentificación formados por los máximos especialistas en cada caso. Las enormes sumas de dinero que mueven el mercado del arte en la actualidad hacen que estas cuestiones tomen una notable relevancia. Una opinión incorrecta o que desvalorice una obra de un propietario privado puede tener una responsabilidad penal.

A modo de reflexión final, he de decir que estos hechos que he tratado de detallar y analizar son sólo el producto de la artificiosidad propia de la sociedad y su cultura en la segunda mitad del siglo XX. Podemos verla como una especie de fuga romántica ante un mundo desorientado y necesitado de valores. Se elige la vida ficticia, adulterada, porque, en la cultura del bienestar, la realidad no podría ser tan bella como la ficción. Pero en este momento histórico no se huye, como hicieron en su momento los románticos, de la realidad social a la naturaleza. La huida, y esto justifica el éxito de la actividad de Elmyr de Hory, es hacia un mundo más elevado, más excelso y sublime y, sobre todo, más artificioso.

32 "Accidente se dice de lo que se encuentra en un ser y puede afirmarse con verdad, pero que no es, sin embargo, ni necesario ni ordinario"... "El accidente se produce, existe, pero no tiene la causa en si mismo, y sólo existe en virtud de otra cosa". (Aristóteles: Metafisica, libro V, XXX).

33 Francis O'Connor, "Autentificación de las atribuciones de obras de arte", El Experto frente al objeto. Madrid: Editorial Marcial Pons, (2011), p. 41. 